\title{
CHARACTERISTIC FEATURES OF THE PHARYNGEAL CAVITY OF THE LAUGHING DOVE (STREPTOPELIA SENEGALENSIS AEGYPTIACA) AND JAPANESE QUAIL (COTURNIX COTURNIX)
}

\author{
FATMA A. MADKOUR \\ Department of Anatomy and Embryology, Faculty of Veterinary Medicine, \\ South Valley University, Qena 83523, Egypt.
}

Received: 9 September 2018; Accepted: 16 October 2018

\begin{abstract}
The purpose of this study was to investigate comparative morphology and morphometry of the pharyngeal cavity of laughing dove (LD) and Japanese quail (JQ) using seven adults of each bird. The length of the pharyngeal roof in JQ was double that of LD but that of the pharyngeal floor was nearly equal in both birds. The ratio of pharyngeal roof length to the total length of the oropharyngeal roof was $13.64 \%$ and $27.18 \%$ in LD and JQ respectively while that of the pharyngeal floor length constituted $34 \%$ in both birds. The surface of the pharyngeal roof in LD was free from papillae with few openings of the sphenopterygoid salivary glands, however, in JQ numerous openings of these glands were scattered between different sizes conical shaped pharyngeal papillae. The openings of the posterior lingual salivary glands at the root of tongue were numerous in LD but they were few in JQ. The laryngeal mound was triangular shape in LD and like heart on playing card in JQ. Behind to caudal commissure of the glottis, the caudal aspect of the laryngeal mound was characterized by V-shaped row of pyramidal-like papillae in LD. While in JQ these papillae which arranged in 3 transverse rows were conical shaped with pointed apices occupied the area extended from the caudal commissure of glottis to the pharyngoesophageal junction. In LD abundant openings of cricoarytenoid salivary glands were arranged in a longitudinal manner on each side of the caudal third of laryngeal mound but few numbers of them were observed in JQ.
\end{abstract}

Key words: SEM; pharynx; glottis; laughing dove; Japanese quail.

\section{INTRODUCTION}

LD is widely distributed in scrub, becoming very domesticated in Africa, the Middle East and the Indian Subcontinent (Ticehurst, 1923, Ali and Ripley, 1981). JQ is mainly distributed in East Asia and Russia (Barilani et al., 2005, Puigcerver et al., 2007, Pappas, 2013). In bird, oropharynx denotes the combined cavity that extends from the beak to the esophagus due to absence of soft palate (Dyce et al., 2009). The pharyngeal cavity delimited from the oral cavity at point between the choanal and infundibular slits (King and McLelland, 1984). In birds, tongue participates with the jaw and pharynx in generating carefully coordinated movement during various behaviours such as feeding and drinking (Homberger and Meyers, 1989). Birds have different structures of

Corresponding author: FATMA A. MADKOUR

E-mail address: madkour.fatma@yahoo.com

Present address: Department of Anatomy and Embryology, Faculty of Veterinary Medicine, South Valley University, Qena 83523, Egypt. their oropharyngeal cavity due to differences in feeding habits, so the characteristic features of the avian oropharyngeal cavity are essential to identify the structural variations that may influence nutrition, food intake, and ingestion (Jayachitra et al., 2015). The objective of this study is to attribute the pharyngeal cavity of the laughing dove and Japanese quail of different habits and the findings of this study might be added new data to the avian anatomy literature.

\section{MATERIALS AND METHODS}

Seven adult healthy birds of each laughing doves (LD) $(94.26 \pm 8.02 \mathrm{gm})$ were collected from bird hunters in Qena governorate, Egypt and of Japanese quails (JQ) $(235.67 \pm 2.5 \mathrm{gm})$ collected from researcher's farm in South Valley University, Qena governorate, Egypt. The heads of the carcasses were dissected after sacrificed and good bleeding. For gross studies, 5 heads of each bird were used, the angles of the beaks were incised, and the pharyngeal roof and floor were dissected then fixed in $10 \%$ 
neutral buffered formalin. The various gross morphological features for each bird were examined in details and the different measurements in millimeters (mean \pm S.E.) of the studied parts of pharyngeal roof and floor, were taken out using Precision Digital Vernier Caliper. All measurements were statistically analyzed by the Statistical Package for Social Science (SPSS) software program, version 17.0 (Argyrous, 2005). For SEM studies, two heads of each bird were used. Representative specimens from pharyngeal roof and floor were washed several times with normal saline and then fixed in a mixture of $2.5 \%$ paraformaldehyde and $5 \%$ glutaraldehyde in $0.1 \mathrm{M}$ sodium phosphate buffer, $\mathrm{pH} 7.3$, at $4{ }^{\circ} \mathrm{C}$ for $24 \mathrm{~h}$. Thereafter, they were washed 4 times for $5 \mathrm{~min}$ in the fixation buffer and postfixed in $1 \%$ osmic acid in $0.1 \mathrm{M}$ sodium phosphate buffer for further $2 \mathrm{~h}$ at room temperature, followed by washing with $0.1 \mathrm{M}$ sodium phosphate buffer for $15 \mathrm{~min} 4$ times. The samples were dehydrated using increasing concentrations of alcohol: 50,70 , and $90 \%$ for $30 \mathrm{~min}$ at each concentration and $100 \%$ for 2 days (several changes) followed by isoamyl acetate for 2 days. The dehydrated samples were subjected to critical point drying with a Polaron apparatus. Finally, they were coated with gold using JEOL-1100 E ion sputtering device and examined with a JEOL scanning electron microscope (JSM $5500 \mathrm{LV})$ at $10 \mathrm{kV}$.

\section{RESULTS}

\section{Pharyngeal roof}

The roof of the pharynx extended from the line of demarcation between choanal and infundibular slits to pharyngoesophageal junction. The length of the pharyngeal roof was shorter in LD than in JQ. It measured $3.39 \mathrm{~mm}, 7.52 \mathrm{~mm}$ and constituted $13.64 \%$, $27.18 \%$ of the total length of the oropharyngeal roof in LD and JQ respectively. The surface of the pharyngeal roof in LD appeared smooth free from papillae but in JQ it was characterized by fine small caudally directed papillae. The terminal part of the pharyngeal roof of LD was elevated as transverse mucosal fold at the junction with esophagus but this junction demarcated by a fine transverse row of papillae in JQ. The pharyngeal roof occupied by infundibular slit which measured $2.53 \mathrm{~mm}, 3.83 \mathrm{~mm}$ and constituted from the pharyngeal roof length $74.63 \%, 50.93 \%$ in LD and JQ respectively (Fig.1A, B).

By SEM, in LD, the surface of the pharyngeal roof on each side of the infundibular slit was smooth free from papillae and showed few openings of the sphenopterygoid salivary glands increased in number caudally till the pharyngoesophageal junction. This junction was demarcated by transverse serrated appearance mucosal fold. The infundibular slit was represented by an elongated opening; its edges were smooth free from papillae (Fig. 2A, C). The surface of the pharyngeal roof of JQ was characterized by different sizes conical shaped papillae with pointed apices, these papillae more concentrated near the infundibular slit which increased in size caudally toward the pharyngoesophageal junction. This junction was demarcated by well-marked transverse row papillae which consisted of large wedge-shaped papillae. Numerous openings of sphenopterygoid salivary glands were scattered between these papillae. The infundibular slit was wider an elongated opening, its edges included caudally directed papillae. This slit continued caudally by a shallow groove which considered the continuation of the caudal commissure of the slit (Fig. 2B, D).

\section{Pharyngeal floor}

The floor of the pharynx extended from the row of the caudally directed lingual papillae to pharyngoesophageal junction. The length of the pharyngeal floor measured $8.13 \mathrm{~mm}$ in $\mathrm{LD}$ and $9.41 \mathrm{~mm}$ in JQ, constituted in both birds about $34 \%$ of the total length of the oropharyngeal floor. The floor of the pharynx consisted of root of tongue and laryngeal mound. The root of tongue demarcated from body by one row of caudally directed papillae. It measured $2.14 \mathrm{~mm}, 3.01 \mathrm{~mm}$ and constituted $26.32 \%$, and $31.98 \%$ of the pharyngeal floor length in LD and JQ respectively. The laryngeal mound was triangular shape in LD and like heart on playing card in JQ. It measured $5.99 \mathrm{~mm}, 6.40 \mathrm{~mm}$ and constituted $73.67 \%$, $68.01 \%$ of pharyngeal floor length in LD and JQ respectively. The laryngeal mound contained laryngeal inlet (glottis) which lied opposite to wide part of choanal slit and lead into the cavity of the larynx. This slit was wedge shaped and measured $2.89 \mathrm{~mm}$ length in LD; its rostral commissure wider than caudal one. While in JQ, the slit measured 3.55 $\mathrm{mm}$ length, its edges were marked by mucosal lips which were slightly elevated above the surface of the laryngeal mound and its caudal commissure continued caudally by short narrow sulcus. The terminal part of the pharyngeal floor of LD was demarcated from esophagus by one row of caudally directed papillae arranged in $\mathrm{V}$-shaped row while in JQ demarcated by 2rows of papillae (Fig. 1C, D).

By SEM, V-shaped row processes-like papillae between body and root of tongue in LD increased in size lateralwards while in JQ these papillae were cactus leaf-like and also increased in size lateralwards. Openings of the posterior lingual salivary glands were demonstrated at the middle part of lingual root which increased caudally toward rostral commissure of glottis. These openings were numerous in LD, but they were fewer in JQ (Fig. 3A, B). The glottis of the laryngeal mound was widest at the middle in LD while in JQ had the same width along its length. Besides the rims of glottis of JQ 
conical caudally directed papillae were observed which increased in number caudally (Fig. 4A, B). By higher magnification, various sizes of openings of intraepithelial glands with ciliated cells were demonstrated near rims of glottis in LD but these openings were away from rims of glottis by short distance in JQ (Fig. 4C, D). Behind the caudal commissure of the glottis of LD, the caudal part of laryngeal mound was characterized by $\mathrm{V}$-shaped row pyramidal-like papillae decreased in size medialwards which demarcated from pharyngoesophageal junction. These papillae were arranged in 3 transverse rows in JQ, they were conical shaped with pointed apices occupied the area extended from the caudal commissure to the pharyngoesophageal junction; the papillae of the most rostral row were generally larger in size and numerous while those of the second row were smallest and fewer in number than the other rows. Abundant openings of caudal cricoarytenoid salivary glands were arranged in a longitudinal manner on each side of the caudal third of laryngeal mound in LD but they were few numbers in JQ (Fig. 5A, B).

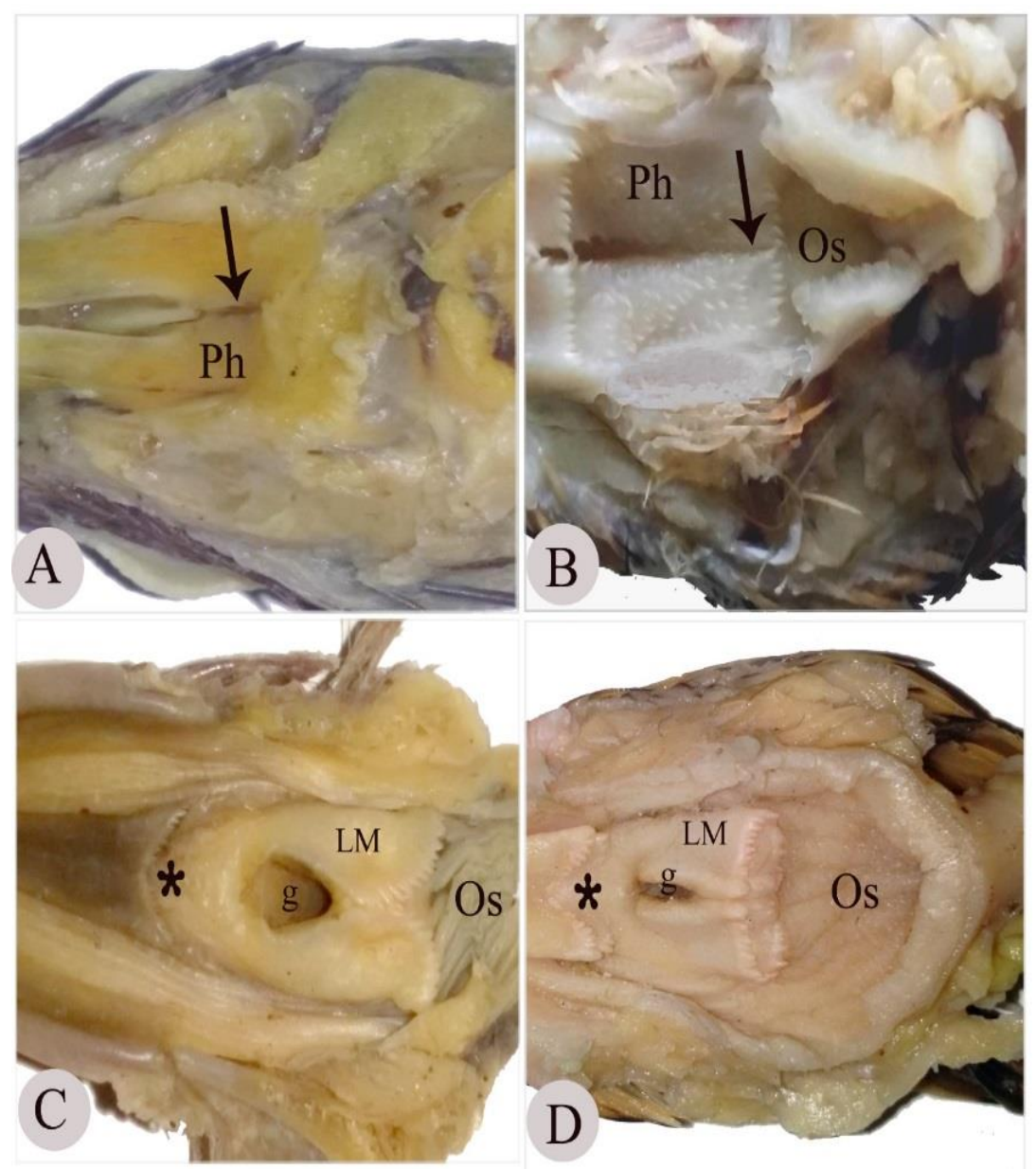

Fig.1: Photograph of the pharyngeal cavity of laughing dove (A\&C) and of Japanese quail (B\&D) showing pharyngeal roof $(\mathrm{Ph})$, infundibular slit (arrow), esophagus (OS), root of tongue (star), laryngeal mound (LM), glottis (g) 


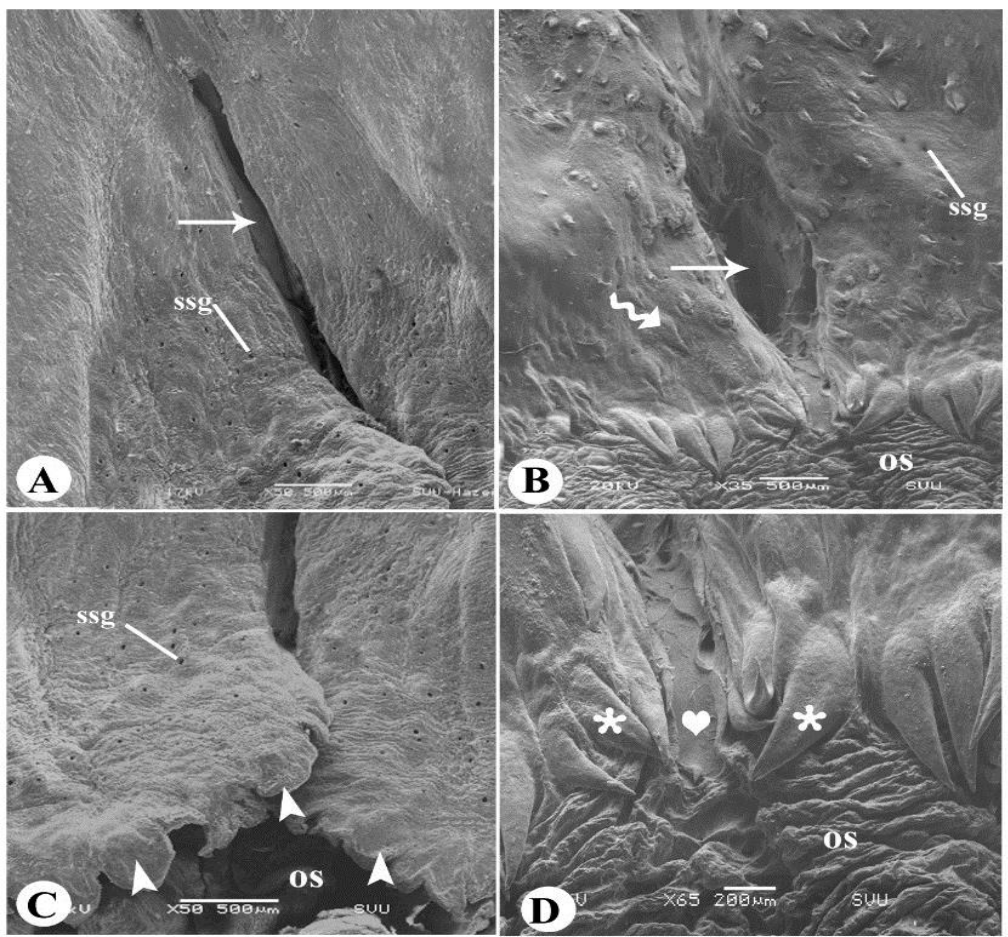

Fig.2: Scanning electron micrograph of the pharyngeal roof of laughing dove (A, C) and of Japanese quail (B, D) showing esophagus (os), infundibular slit (arrow), openings of sphenopterygoid glands (ssg), conical shaped papillae (twisted arrow), shallow groove (heart-shape) at the caudal commissure of the infundibular slit, transverse serrated appearance mucosal fold (arrowheads) and transverse row conicalshaped papillae (stars) at pharyngoesophageal junction.

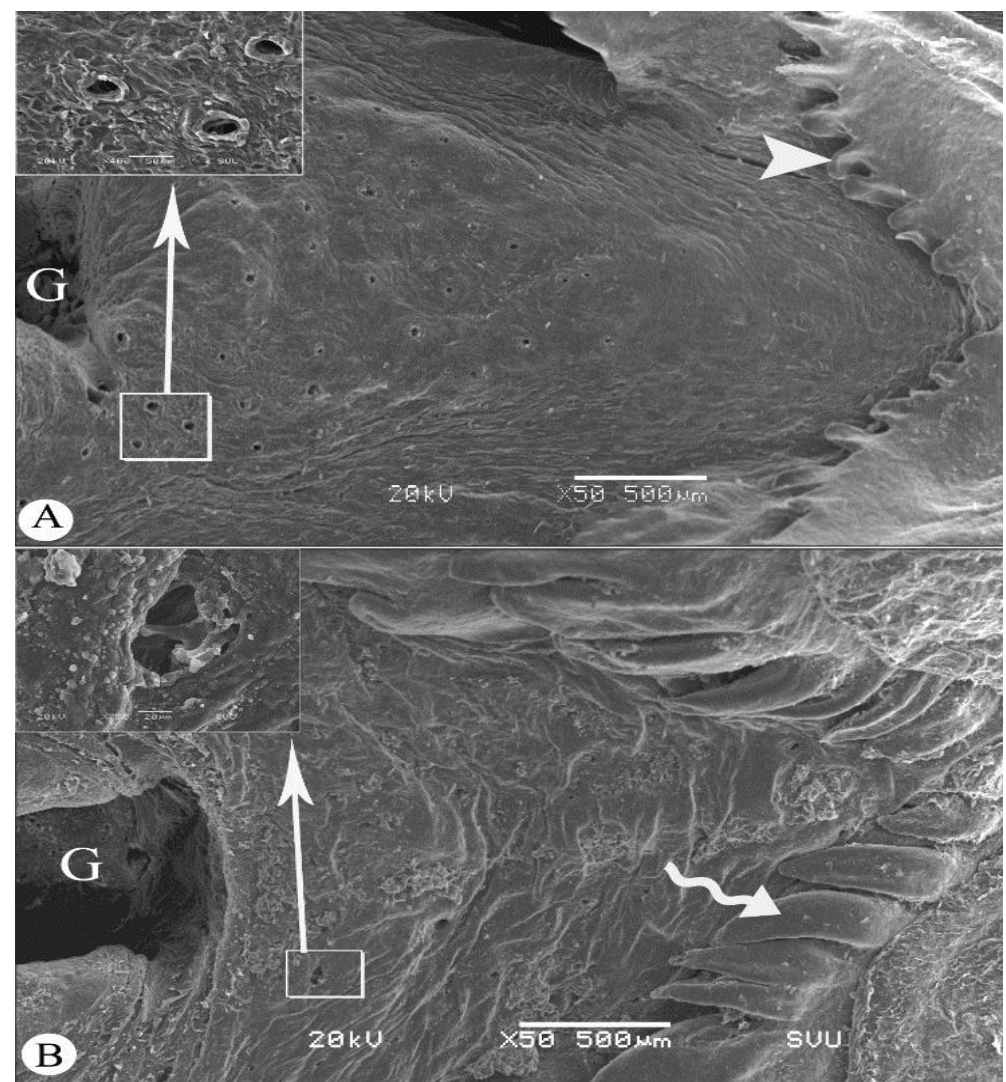

Fig.3: Scanning electron micrograph of the root of the tongue of laughing dove (A) and of Japanese quail (B) showing openings of posterior lingual salivary glands (square), V-shaped row processes like papillae (arrowhead), cactus leaf-like papillae (spiral arrow) between body and root of tongue, glottis (G). 


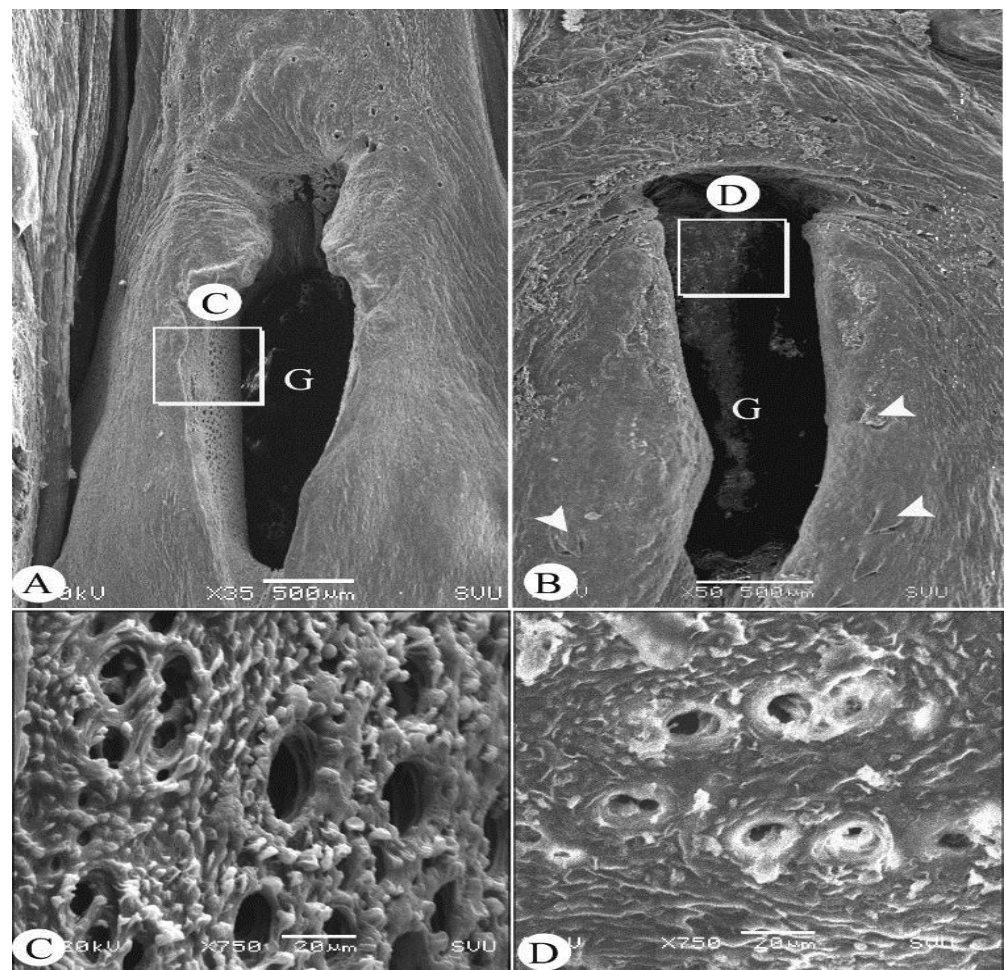

Fig.4: Scanning electron micrograph of the laryngeal mound of laughing dove (A\&C) and of Japanese quail (B\&D) showing glottis (G), conical caudally directed papillae (arrowheads) beside the rims of glottis, various sizes openings of intraepithelial glands within glottis (square), (C\&D) higher magnification of openings of intraepithelial glands within glottis.
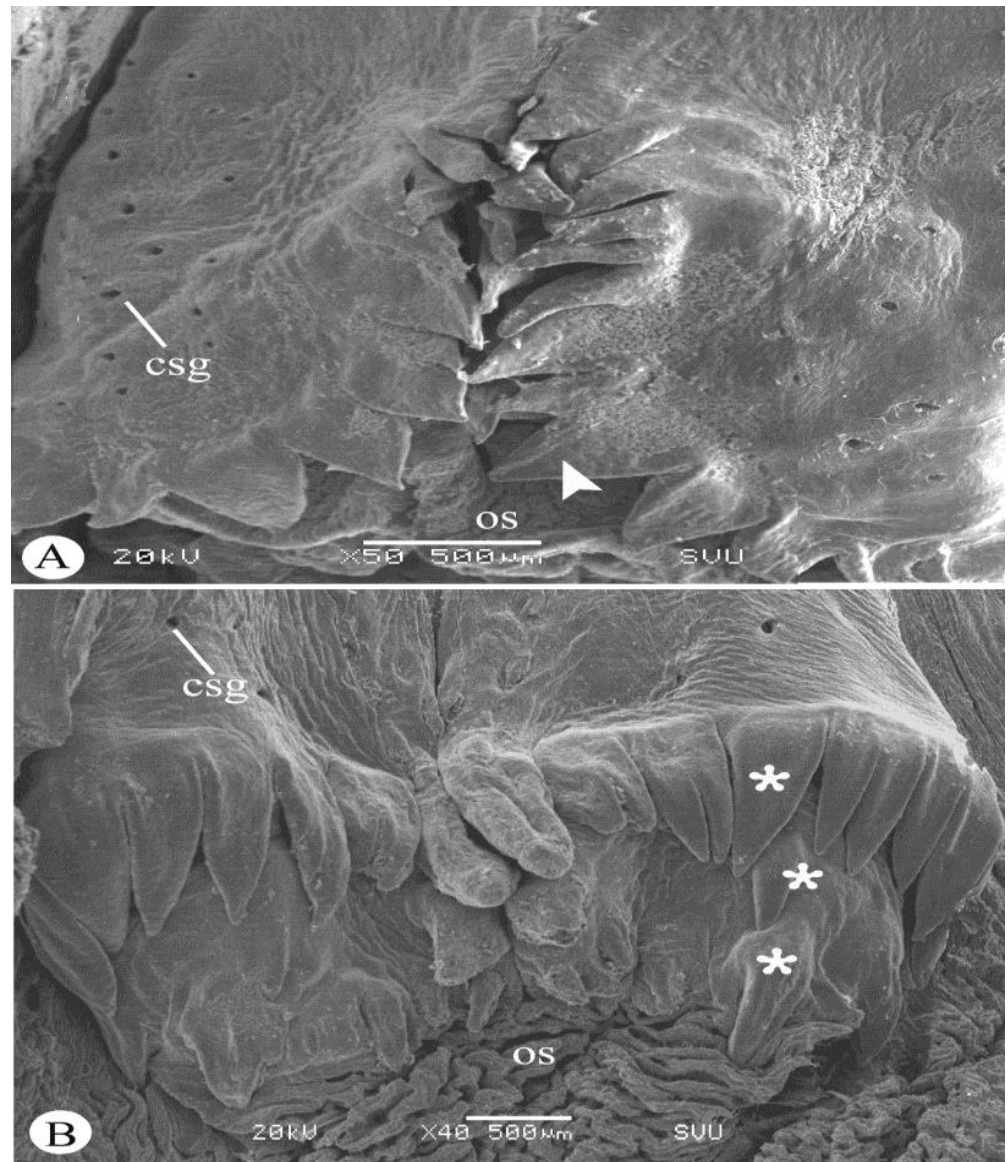

Fig.5: Scanning electron micrograph of the caudal third of the laryngeal mound of laughing dove (A) and of Japanese quail (B) showing openings of posterior cricoarytenoid salivary glands (csg), V-shaped row pyramidal-like papillae decreased in size medialwards (arrowhead), 3 transverse rows conical shaped papillae (stars) demarcated from esophagus (os). 


\section{DISCUSSION}

In this investigation, the surface of the pharyngeal roof of LD was free from papillae while that of JQ was characterized by fine small variable papillae. The findings of LD agreed with that obtained by Abumandour (2014) in falcon and Moussa and Hassan (2013) in cattle egret. In the same line with Madkour (2011) in ducks and Sayed et al. (2016) in turkey, the present scanning electron microscopical results in JQ showed numerous openings of sphenopterygoid salivary glands scattered between numerous different sized conical shaped caudally directed pharyngeal papillae. Moreover, this result added in LD that few openings of the sphenopterygoid salivary glands were observed on the pharyngeal roof. The secretion of the salivary glands in LD and JQ is thought to aid swallowing of dry foods as reported in Nutcracker (Jackowiak et al., 2010). From the current morphometrical study, it was revealed that the ratio of the length of the pharyngeal roof to that of the oropharyngeal roof was $13.64 \%$ in LD and $27.18 \%$ in JQ. Nearly like our findings in LD mentioned in turkey (Sayed et al., 2016). In 60 days old duck, the length of the pharyngeal roof was $15.19 \%$ of the oropharyngeal roof length (Madkour, 2011). On other hand, the length of the pharyngeal floor to that of the oropharyngeal floor was recorded about $34 \%$ in studied birds.

The infundibular slit measured $2.53 \mathrm{~mm}$ in $\mathrm{LD}$ and $3.83 \mathrm{~mm}$ long in JQ. In fowl, it was $0.61 \pm 0.02 \mathrm{~cm}$ long (Gupta et al., 2015), 8.04mm in duck (Madkour, 2011), 4.65mm in southern lapwing (Vanellus chilensis) (Erdoğan and Pérez, 2015) and $1.97 \mathrm{~cm}$ in ostrich (Tivane, 2008). Moreover, in falcon the infundibular cleft is very narrow, small, shorter, reach $8 \mathrm{ml}$ in long (Abumandour, 2014). When viewed with SEM, the edges of the infundibular slit in LD were free from papillae while caudally directed papillae were recognized in JQ. In turkey, a short transverse row of papillae located on both sides of the infundibular slit (Sayed et al., 2016). The latter authors added that there was a shallow groove occupied by longitudinal mucosal folds separating the choanal cleft from the infundibular cleft while in raven there was a transversal fold between two slits (Erdogan and Alan, 2012). On other hand, Sayed et al. (2016) in turkey and Madkour (2011) in duck recorded that the infundibular slit continued caudally with a shallow groove like findings of JQ. Functionally, the infundibular opening and glottis are reflexly closed to prevent food from entering the infundibular and laryngeal cavities (McLelland, 1975, King and McLelland, 1984).

By SEM, in examined birds the root of the tongue demarcated from the body by $\mathrm{V}$-shaped row of papillae increased in size lateralwards. However, this row of papillae is absent in the cattle egret except one lateral long papilla on both sides of the base of the tongue (Moussa and Hassan, 2013). In ostrich, the root of the tongue was demarcated from body by presence of the flat fold with lateral processes sliding over lingual root (Jackowiak and Ludwig, 2008). Moussa and Hassan (2013) clarified that the direction of the food toward esophagus and prevent its regurgitation performed by help of this row. In the examined birds, the length of the glottis which was very short in comparison with other birds as reported in the obtained literature. It was $2.89 \mathrm{~mm}$ in LD and $3.55 \mathrm{~mm}$ in JQ. It was $12.91 \mathrm{~mm}$ in geese (Mohamed et al., 2018), $13.6 \mathrm{~mm}$ in turkey (Saleh, 2013). But the ostrich had very long glottis measuring $33.3 \mathrm{~mm}$ (Tadjalli et al., 2008).

The present work showed that the pharyngoesophageal junction at the pharyngeal roof in LD was demarcated by transverse serrated appearance mucosal fold. Like the description of Ali and Ripley (1981) in ostrich while in JQ it was obvious from the present findings that this junction demarcated by well-marked transverse row papillae which consisted of large wedge-shaped papillae similar to that mentioned in other birds (Hassouna, 2002, Jayachitra et al., 2015). In duck, the papillae at the pharyngoesophageal junction have the appearance of nails of the carnivores (Madkour, 2011). Moreover, in turkey, the papillae of this junction were caudally directed and elongated conical shaped, the lateral located papillae were smaller than the medial ones (Sayed et al., 2016). On other hand, Tadjalli et al. (2008) in ostrich illustrated that lack of a transverse row of papillae at the junction with the esophagus. Furthermore, the current study showed that the caudal part of laryngeal mound occupied by $\mathrm{V}$-shaped row pyramidal-like papillae in LD and 3 transverse rows of conical shaped papillae with pointed apices. In this connection, in geese, numerous closely packed caudally directed and different sized pharyngeal papillae occupied the area behind to the laryngeal inlet (Mohamed et al., 2018). However, in red jungle fowl, a single row of pharyngeal papillae was observed behind glottis (Kadhim et al., 2011). The caudally directed papillae on the laryngeal eminence and the pharyngeal roof simplify the direction of the bolus towards the esophagus (McLelland, 1975, King and McLelland, 1984). Thus the distribution and number of the pharyngeal papillae of JQ was more than that of LD due to behavior of JQ in eating which is ground bird and eat rapacity.

\section{ACKNOWLEDGMENT}

The author is offer thanks and gratitude to the Electron Microscopy Unit technicians for their assistance and researcher's farm at South Valley University which thrift enough number of birds to complete the research. 


\section{REFERENCES}

Abumandour, M.M. (2014): Gross anatomical studies of the oropharyngeal cavity in Eurasian hobby (Falconinae: Falco Subbuteo, Linnaeus 1758). Journal of Life Sciences Research 1(4): 80-92.

Ali, S. and Ripley, S.D: (1981): Handbook of the Birds of India and Pakistan. New Delhi: Oxford University Press.

Argyrous, G. (2005): Statistics for research; with a guide to SPSS. Sage, London.

Barilani, M.; Derégnaucourt, S.; Gallego, S.; Galli, L.; Mucci, N.; Piombo, R.; Puigcerver, M.; Rimondi, S.; Rodríguez-Teijeiro, J. and Spanò, $S$. (2005): Detecting hybridization in wild (Coturnix c. coturnix) and domesticated (Coturnix c. japonica) quail populations. Biological Conservation. 126(4): 445-455.

Dyce, K.M.; Sack, W.O. and Wensing, C.J.G. (2009): Textbook of Veterinary Anatomy, Elsevier Health Sciences.Philadelphia, London, New York and Sydney.

Erdogan, S. and Alan, A. (2012): Gross anatomical and scanning electron microscopic studies of the oropharyngeal cavity in the European magpie (Pica pica) and the common raven (Corvus corax). Microscopy research and technique. 75(3): 379-387.

Erdoğan, S. and Pérez, W. (2015): Anatomical and scanning electron microscopic characteristics of the oropharyngeal cavity (tongue, palate and laryngeal entrance) in the southern lapwing (Charadriidae: Vanellus chilensis, Molina 1782). Acta Zoologica 96(2): 264-272.

Gupta, S.K.; Archana, P. and Farooqui, M. (2015): Anatomy of oropharyngeal cavity of fowl (Gallus domesticus). Indian Journal of Veterinary Anatomy. 27(1): 12-14.

Hassouna, E. (2002): Morphyological studies on the phyarynged cavity of duck, Anas boushius domesticus. Assiut Veterinary Medical Journal (Egypt). 47(49): 21-41.

Homberger, D.G. and Meyers, R.A. (1989): Morphology of the lingual apparatus of the domestic chicken, Gallus gallus, with special attention to the structure of the fasciae. Developmental Dynamics. 186(3): 217-257.

Jackowiak, H. and Ludwig, M. (2008): Light and scanning electron microscopic study of the structure of the ostrich (Strutio camelus) tongue. Zoological Science. 25(2): 188-194.

Jackowiak, H.; Skieresz-Szewczyk, K.; Kwieciński, Z.; Trzcielińska-Lorych, J. and Godynicki, S. (2010): Functional morphology of the tongue in the nutcracker (Nucifraga caryocatactes). Zoological Science. 27(7): 589-594.
Jayachitra, S.; Balasundaram, K.; Iniyah, K.; Sivagnanam, S. and Tamilselvan, S. (2015): Morphology of oropharyngeal cavity in guinea fowl (Numida meleagris). International Journal of Advanced Multidisciplinary Research IJAMR. 2: 99-102.

Kadhim, K.K.; Zuki, A.; Babjee, S.; Noordin, M. and Zamri-Saad, M. (2011): Morphological and histochemical observations of the red jungle fowl tongue, Gallus gallus. African Journal of Biotechnology. 10(48): 9969-9977.

King, A.S. and McLelland, J. (1984): Birds, their structure and function, Bailliere Tindall, $1 \mathrm{St}$. Annes Road.

Madkour, F.A.M. (2011): Some developmental studies on the roof of the oropharynx of the duck. M.V.Sc. thesis, South Valley University, Egypt.

McLelland, J. (1975): Aves Digestive System: In Sission and Grossman's, The Anatomy of the Domestic Animals, Rev. R. Getty. W.B. Saunders Company. Philadelphia and London.

Mohamed, S.A.; Abdelsabour-Khalaf, $M$. and Abdelhakeem, F. (2018): Morphological Characterization Of The Laryngeal Mound Of The Egyptian Geese. Assiut Vet. Med. J. 64(156): 1-8.

Moussa, E.A. and Hassan, S.A. (2013): Comparative gross and surface morphology of the oropharynx of the hooded crow (Corvus cornix) and the cattle egret (Bubulcus ibis). Journal of Veterinary Anatomy. 6(1): 1-15.

Pappas, J. (2013): Coturnix japonica. Animal Diversity Web.

Puigcerver, M.; Vinyoles, D. and Rodríguez-Teijeiro, J.D. (2007): Does restocking with Japanese quail or hybrids affect native populations of common quail Coturnix coturnix. Biological Conservation 136(4): 628-635.

Saleh, A.M. (2013): Macro- and Micromorphological studies on the laryngeal mound of Turkey. Assiut Vet. Med. J. 59: 88-94.

Sayed, R.K.; Saleh, A.M.; Ahmed, A.K. and Abdalla, K.E. (2016): Gross Anatomical, Light and Scanning Electron Microscopic Studies on the Pharyngeal Roof of Turkey (Meleagris gallopavo): Comparative Study. Journal of Advanced Veterinary Research. 6(4): 112-117.

Tadjalli, M.; Mansouri, S.H. and Poostpasand, A. (2008): Gross anatomy of the oropharyngeal cavity in the ostrich (Struthio camelus).Iranian Journal of Veterinary Research. 9(4): 316-323.

Ticehurst, C.B. (1923): The Birds of Sind. (Part V.). Ibis 65(3): 438-473.

Tivane, C. (2008): A morphological study of the oropharynx and oesophagus of the ostrich (Struthio camelus), MSc dissertation. 


\section{الصفات المميزة للتجويف البلعومي في اليمام الضاحك والسمان الياباني}

\section{فاطمه عباس محمد مدكور}

E-mail: madkour.fatma@yahoo.com Assiut University web-site: www.aun.edu.eg

الغرض من هذه الدر اسة هو در اسة التوصيف الظاهرى والقياسـات الثكلية للتجويف البلعومي في اليمام الضـاحك و السمان الياباني

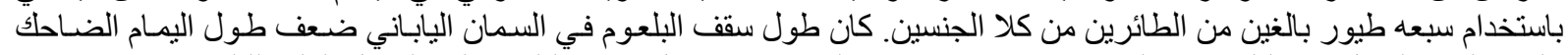

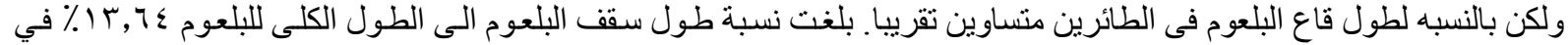

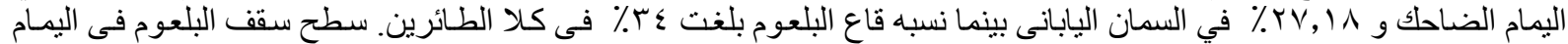

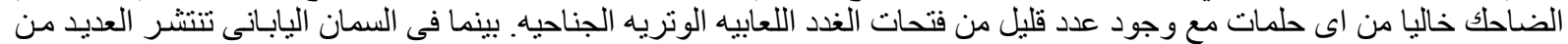

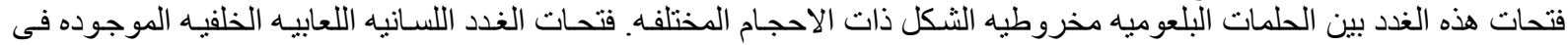

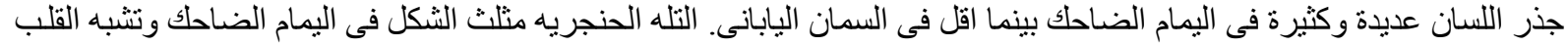

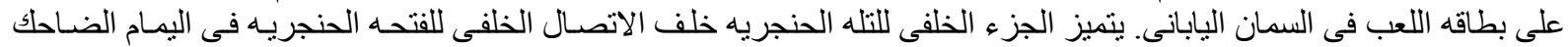

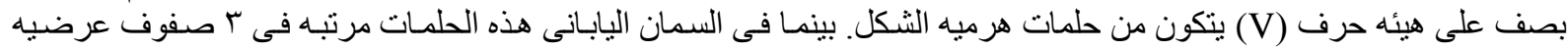

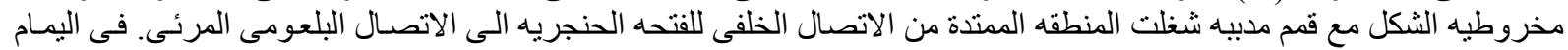

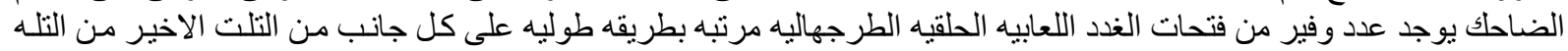

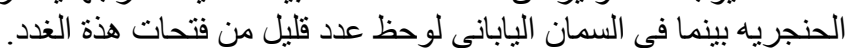

